\title{
Sustainable Development Mechanism of Avoiding Group Conflict and Symbiosis: A Study on Labor Disputes
}

\author{
Jing Dong, ${ }^{1}$ Huizhang Shen $\mathbb{D}^{1}{ }^{1}$ and Jidi Zhao ${ }^{2}$ \\ ${ }^{1}$ Antai College of Economics and Management, Shanghai Jiao Tong University, Shanghai 200030, China \\ ${ }^{2}$ School of Public Administration, East China Normal University, Shanghai 200062, China \\ Correspondence should be addressed to Huizhang Shen; hzshen@sjtu.edu.cn
}

Received 2 May 2019; Accepted 14 September 2019; Published 3 November 2019

Academic Editor: Átila Bueno

Copyright (c) 2019 Jing Dong et al. This is an open access article distributed under the Creative Commons Attribution License, which permits unrestricted use, distribution, and reproduction in any medium, provided the original work is properly cited.

\begin{abstract}
Group conflict is one of the main human conflicts in the history of human development and results in various forms such as competition, fight, riot, or war in extreme cases and compromise, negotiation, or cooperation in other cases. The inner essence of the group conflict is competitors vying for resource control. If the conflict ends up at a situation where one party overwhelms the other, it will actually bring destructive results to both sides. Is there a solution to avoid fierce conflicts and to achieve a win-win situation? Is there a unified model by which different forms of conflicts can be interpreted and studied? The purpose of this paper was to address these problems and attempt to establish such a unified model and to use it to analyze the dynamic relationship between the employees and their employers in the viewpoint of group conflict and symbiosis. By changing coefficients of the unified model, the two sides, employers and employees, could be in different situations such as employer win, employee win, loselose, and win-win. Keeping other coefficients unchanged, we found and proved that there is a win-win strategy space of the payoff rate. Two parties chose strategy within the space can achieve optimal status in long run.
\end{abstract}

\section{Introduction}

Force disputes and economic conflicts between neighboring countries, among different regions, ethnic groups, and social groups, and even world wars are all originated from "resource allocation," in which political conflicts are also usually ended with. Resources here refer to natural resources, economic resources, social resources, environmental resources, and so on.

It was reported in 1993 for the first time that more than 8,700 social group events occurred in China in that year. By the end of October 31st, 2016, there have been 2 million social group events occurred within the past 24 years. Performing cluster analysis on the causes of group conflicts, we concluded four major categories: land acquisition and demolition, environmental pollution, labor disputes, and unfair law enforcement. Nearly $50 \%$ of group conflicts were caused by land acquisition and demolition, about $30 \%$ were caused by environmental pollution and labor disputes, and the other $20 \%$ were caused by law enforcement and other social contradictions.

As mentioned above, the proportion of land acquisition and demolition conflict, environmental pollution conflict, and labor conflict reached $80 \%$. Through further quantitative analysis, it was found that the basic contradiction of social group events is "resource allocation." All land acquisition and demolition conflicts are originated from land resources allocation; all environmental pollution conflicts are originated from resource allocation relevant to the environment; the occurrence of all labor conflicts also cannot be separated from employment resources allocation, human resources and remuneration allocation, and the price of human resources.

In the case of labor conflicts, employers cannot meet the expectations of workers for labor remuneration, which can easily lead to labor protests, petitions, strikes, and even social unrest. In reality, employers pay more attention to the level of labor remuneration from the whole profits and losses, 
while labors care more about the amount they think they deserve based on current social conditions. Resulting from different standpoints, different opinions, and two sides in a stalemate, conflicts occur from time to time and become one of the main problems in the whole society.

Labor conflicts or labor disputes refer to employers and employees negotiating on payment or related welfare from respective positions. Some conflicts were solved soon, while other conflicts not only lasted for a long time but led to the suffering of both employers and employees from large economic losses, causing huge social influence at the same time. Can we find a win-win solution between employees and employers to reduce or avoid fierce conflicts and ensure sustainable cooperation? Then, can we find a more general, sustainable, collaborative, and win-win situation which caters to all kinds of groups based on conflicts of "resource allocation"?

Much effort has been devoted to the study of labor disputes from many perspectives, but few scholars have made research on this issue from the perspective of mathematical modeling. Chan and Hui analyzed the labor strike in China and concluded there would be transition in the collective negotiation process of China from the aspects of political economics [1]. Chen discussed the role Chinese trade union played in labor disputes and analyzed the effect of its double identity in market reform period in handling different levels of economical demands of labors [2]. Shen and Benson thought the occurrence of labors and trade unions as a first step towards more genuine collective bargaining in settling labor disputes [3]. Oderanti et al. designed a flexible decision support scheme using the fuzzy interface system for wage negotiation between employers and employees. The game strategies aimed to help two parties reach a mutually agreeable rate for wage increasing sustainably in the future [4]. Houba and Wen settled questions concerning on the contract negotiation model when two parties had different discount factors and discussed the strategy for the employees or unions to achieve an agreement of equilibrium payoff [5].

Many researches applied different approaches in studying group conflicts, such as diffusion models, game theory, and psychology. Well-known diffusion models have been adopted to study the competition relationship. Morris and Pratt addressed the special case that a dominant competitor at equilibrium is replaced after the introduction of a small population of an invading competitor with a competitive advantage and analyzed the behavior of the Lotka-Volterra competition (LVC) equations in such a case. $\mathrm{He}$ also compared the dynamics of LVC competitive substitution to that of several well-known substitution models [6]. In the viewpoint of technological forecasting of competition, Lee et al. analyzed the dynamic relationship between the Korean Stock Exchange (KSE) and Korea Securities Dealers Automated Quotation (KOSDAQ), two competing markets at the Korean stock market. They adopted the Lotka-Volterra system of equations to represent the competitive situations of the Korean stock market and found the two markets change from a predator-prey relationship to a symbiotic relationship and finally to a pure competition relationship [7] Dercole and Geritz investigated the competition between two groups of similar agents and classified the competition scenarios in the three levels of genericity: away from singularity, close to a generic singular strategy, and close to degenerate singular strategies [8].

Pietraszewski addressed the conflict problem from a psychological point of view [9]. He considered the psychological representation of coalitional conflict and described all the possible interaction ways in a group conflict: alliance, defense, generalization, and displacement. The analysis of the cost/benefit calculations of each agent's role within these interactions provides a precise way to describe the decisions involved in a group conflict.

Some researchers also explored the conflict issue using game-theoretic models. Smith and Price looked into the logic of animal conflicts [10] and proposed the evolutionary stable strategy which, if adopted by the majority of the group, cannot be invaded by any mutant strategy that is initially rare. Territorial contest, a particular form of conflict, has been of interest to Mesterton-Gibbons [11] and Gent [12]. Under some conditions, ambiguity existed in who were the first individuals to discover and maintain territories and thus could be respected as land owners. Mesterton-Gibbons and Sherratt developed a pair of game-theoretic models to understand the evolutionary on sequences of this ambiguity [11]. Gent and Shannon found that arbitration and adjudication can help prevent the bargaining process breakdown in the shadow of territorial contest, but such measures only work when the expected ruling reflects the balance of power between parties involved in the contest [12].

However, research that explains the symbiotic issue is sparse [13], let alone addressing both the conflict and the symbiosis in a unifying approach. Nunes et al. introduced two variables, essentiality of consumption and environmental impact, to measure the sustainability performance of socioeconomic systems, and developed the concept of system fitness based on the essentiality balance and relative surplus in a system which can be used to help the management of sustainability in countries, regions, and firms.

This research studies if there exists a unified dynamic mechanism between social group conflicts and symbiosis from the aspect of ecological dynamics. We mainly focus on labor conflicts. During the process of real labor conflicts, for example, labor conflicts occurred as the result of remuneration all over China in recent years, employees and employers usually negotiated on requirements such as employers modifying payment standard to pay lower wages, employees asking for increasing remuneration, subsidies, and wages, and so on. Employers hoped to reduce remuneration and employees asked for increasing payment, none of them compromised. Then, the climax of negotiations might result in the form of labor strikes, lasting for several hours (e.g., workers from a state-owned enterprise paraded in December 2011 in Chengdu, Sichuan) or more than ten days (e.g., Honda Strike in June 2010 in Foshan, Guangzhou). These conflicts usually negatively affected production operations, ending up as both sides reaching 
a compromise (e.g., in the Honda strike, the final solution was to raise 500 yuan in basic wage for each staff, compared to a raise of 800 yuan required previously by workers). The aim of this research is not to discuss the simple labor agreement relationship between employees and employers or a one-time labor conflict. Instead, we study if it is possible to build a long-term sustainable cooperation relationship, to make two sides obtain higher revenue and achieve win-win between employees and employers.

\section{Feature Analysis on Dynamic Evolution of Industrial Relations}

In most cases, cooperation between employees and employers is not a one-time, but a long-term and continuous relationship. Especially in industries demanding for skills and experience, the training cost will absolutely increase if relations of cooperation change very often. As for labors, life will be undoubtedly unstable if they change jobs frequently. Therefore, it is beneficial for both employees and employers to build a long-time and steady relationship.

What is a long-time and steady relationship? That is, through a reasonable "resource allocation" strategy, resources attained by both sides could always be in a stable situation above the initial value as negotiated.

Employees usually ask for remuneration increase because of various social factors, such as price rise, labor intensity increasing, working hours increasing, social psychological reasons, and so on. On the contrary, employers may execute layoff or reduce wages for the sake of price for raw materials going up or bad losses of enterprises. However, employees and employers usually disagree with each other, thus leading to labor conflicts. Dynamic evolution features between employees and employers are mainly represented as the following aspects:

(1) Employees and employers hope to achieve a win-win situation

Win-win refers to making resources that two sides obtained be continually in a stable situation above the initial value as negotiated by the "resource allocation" strategy. In this research, we assume $\left(X_{0}, Y_{0}\right)$, respectively, represents the minimum deserving resources as contracted at the beginning of cooperation between employees and employers, referred to as the initial value. And we assume $\left(X_{f}, Y_{f}\right)$, respectively, represents the value of resources that employees and employers will obtain in the stable situation. The win-win strategies should satisfy $X_{f}>X_{0}$ and $Y_{f}>Y_{0}$.

(2) Uncertainty of evolution paths

The result of long-time evolution of labor relations is not unique. Win-win is just one of the evolution paths, and it may also turn out to be single win or double lose. It is uncertain that in which path employees and employers will evolve along and which stable situation they will arrive at when adopting different strategies.
(3) Long-time evolution results between employees and employers depend on initial resources

The final evolution results of labor conflicts are also closely related to initial conditions. Different initial conditions will lead to different results.

(4) Mutual interdependence and mutual restraint between employees and employers

Similar to the population in ecological systems, there exists mutual interdependence and mutual restraint between employees and employers

\section{Dynamic Evolution Model of Labor Relations}

The relationship between employees and employers is a special case of ecological problems and is analogous to the dynamics of sheep-grass or lynx-hare. However, this kind of sustainable dynamic evolution is different from the traditional predator-prey ecological problems. The evolution result is the stable solution that two sides continually obtain resources, but not the periodical oscillating solutions in the predator-prey model. This kind of sustainably developing problem is widespread in human society.

In the study of traditional populations and ecological dynamic problems, different dynamic models are used to describe different relationships between species.

The following three set of equations (1)-(3) are the models of two species with competitive relationship, cooperative relationship, and predator-prey relationship [14], respectively, where $X$ and $Y$ represent densities of two species and $a, b, c, d, \beta_{1}$, and $\beta_{2}$ are positive constants:

$$
\begin{aligned}
& \left\{\begin{array}{l}
\dot{X}=a X-c X Y-\beta_{1} X^{2}, \\
\dot{Y}=b Y-d X Y-\beta_{2} Y^{2},
\end{array}\right. \\
& \left\{\begin{array}{l}
\dot{X}=a X+c X Y-\beta_{1} X^{2}, \\
\dot{Y}=b Y+d X Y-\beta_{2} Y^{2},
\end{array}\right. \\
& \left\{\begin{array}{l}
\dot{X}=a X-c X Y-\beta_{1} X^{2}, \\
\dot{Y}=-b Y+d X Y-\beta_{2} Y^{2} .
\end{array}\right.
\end{aligned}
$$

In reality, both sides of a social group conflict are in the same social condition, and the structure of the group itself and the structure of the relationship between groups are also fixed. Therefore, the conflicting social groups follow unified rules when making resource allocation. It is different from traditional populations and ecological dynamic problems, in which different dynamic models are applied to describe the relationship of cooperation, competition, and symbiosis between species. Then, we want to know if there exists a unified model structure which can evolve a competitive, cooperative, and symbiotic relationship only by different coefficients. In other words, the conflicting two sides can combine out relationships of competition, cooperation and symbiosis only by changing strategies (changing coefficients of the unified model structure). By extension, is it possible for the conflicting two sides to sustainably obtain resources through cooperation instead of fierce disputes? 
Based on dynamics theory, the dynamic relationship between employees and employers can be illustrated in Figure 1. $X$ represents the newly acquired resources of employers, $Y$ represents the newly acquired resources of employees, and $a_{1}, a_{2}, b_{1}, b_{2}, c, k, \beta_{1}$, and $\beta_{2}$ are parameters with positive values.

As shown in Figure 1, the rules can be summarized as follows:

(1) The employers make his profit from the primary business and the secondary business, respectively, with a growth rate of $a_{1}$ and $a_{2}$.

(2) Employees get payoffs from employers, including but not limited to base salaries, overtime allowances, and bonuses, which are labor costs for employers. The parameter $c$ represents the payoff rate, and $k$ is a discount rate considering taxes and delayed payments. Therefore, the actual payoff rate for employees is $k c$.

(3) Besides payoffs from employers, employees also get other incomes such as subsidy and bank interest, which increase with a growth rate of $b_{1}$.

(4) Employees have to suffer the cost of living, including but not limited to commuting cost, skill learning cost, and living necessities cost, which increases with a growth rate of $b_{2}$.

(5) There will be a decline in growth in employers' making profits owing to market saturation or raw materials shortage. $\beta_{1}$ represents the decreasing rate of speed of employers' wealth accumulation.

(6) Physical and mental fatigue can hinder employees from working long hours. $\beta_{2}$ represents a decreasing rate in speed for making money by employees.

Thus, the dynamic model can be written as follows:

$$
\left\{\begin{array}{l}
\dot{X}=a_{1} X+a_{2} X-c X Y-\beta_{1} X^{2}, \\
\dot{Y}=b_{1} Y-b_{2} Y+k c X Y-\beta_{2} Y^{2} .
\end{array}\right.
$$

The equations are a generalization of Lotka-Volterra equations.

Among the coefficients in the model, the payoff rate $c$ is the most vital and negotiable one, affecting the resource allocation and production activity. Disputes between employees and employers usually emerge owing to the discrepancy between the expectations of $c$ from the two parties. So $c$ is a decisive parameter in our model.

The feasible region of (4) is shown as follows:

$$
\Omega=\left\{(X, Y) \in \mathbb{R}^{2}: X \geq 0, Y \geq 0\right\} .
$$

The equations of (4) can be rewritten as

$$
\left\{\begin{array}{l}
\dot{X}=X\left[\left(a_{1}+a_{2}\right)-c Y-\beta_{1} X\right], \\
\dot{Y}=Y\left[\left(b_{1}-b_{2}\right)+k c X-\beta_{2} Y\right]
\end{array}\right.
$$

where $X$ and $Y$, corresponding to the newly acquired resources of employers and employees, evolve with time. If set $\left(X_{0}, Y_{0}\right)$ to some specific initial values, with preset values of parameters $a_{1}, a_{2}, b_{1}, b_{2}, c, k, \beta_{1}$, and $\beta_{2}, X$ and $Y$ will

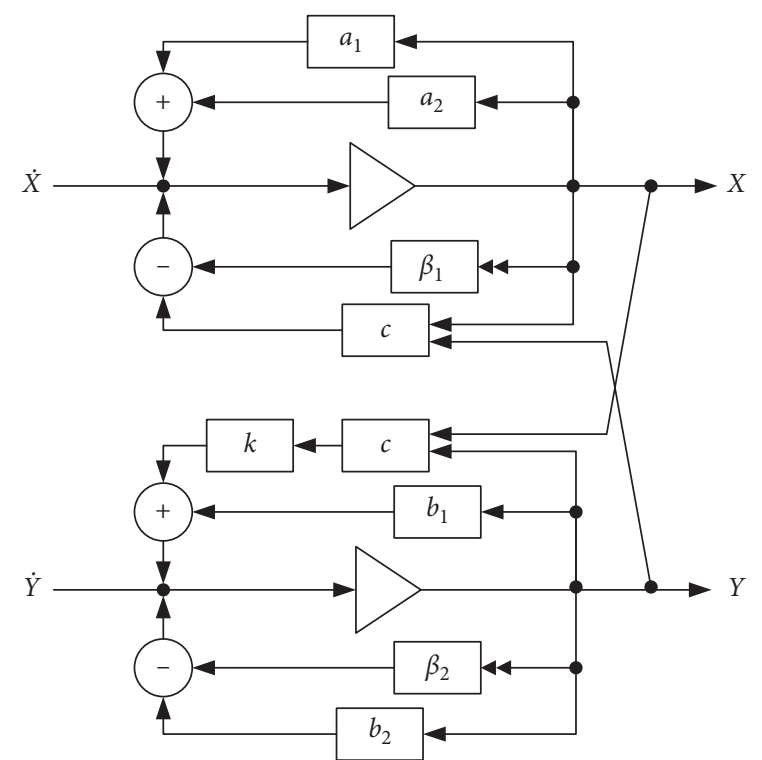

Figure 1: The dynamic relationship of employers and employees in a long-term cooperation (the right triangle " $\triangleright$ " represents the integral operation).

converge to a steady state, which is the fixed point of the evolutionary model, denoted by $P_{f}=\left(X_{f}, Y_{f}\right)$. The definition of fixed point, $\dot{X}=\dot{Y}=0$, leads to

$$
\left\{\begin{array}{l}
\left(a_{1}+a_{2}\right) X\left(1-\frac{\beta_{1}}{a_{1}+a_{2}} X-\frac{c}{a_{1}+a_{2}} Y\right)=0, \\
\left(b_{1}-b_{2}\right) Y\left(1+\frac{k c}{b_{1}-b_{2}} X-\frac{\beta_{2}}{b_{1}-b_{2}} Y\right)=0 .
\end{array}\right.
$$

Thus, we can get four fixed points of the dynamic model from (7) if $b_{1} \neq b_{2}$, which are

$$
\begin{aligned}
& P_{1}=\left(\frac{a_{1}+a_{2}}{\beta_{1}}, 0\right), \\
& P_{2}=\left(0, \frac{b_{1}-b_{2}}{\beta_{2}}\right), \\
& P_{3}=(0,0), \\
& P_{4}=\left(\frac{\left(a_{1}+a_{2}\right) \beta_{2}-\left(b_{1}-b_{2}\right) c}{\beta_{1} \beta_{2}+k c^{2}}, \frac{k\left(a_{1}+a_{2}\right) c+\left(b_{1}-b_{2}\right) \beta_{1}}{\beta_{2} \beta_{1}+k c^{2}}\right) .
\end{aligned}
$$

Define $R_{0}=\left(b_{1}-b_{2}\right) /\left(a_{1}+a_{2}\right)$,

(a) If $R_{0}<-\left(k c / \beta_{1}\right)$, there exist two fixed points $P_{1}$ and $P_{3}$ in $\Omega$, as shown in Figure $2(\mathrm{~d})$

(b) If $-\left(k c / \beta_{1}\right)<R_{0}<0$, there exist three fixed points $P_{1}$, $P_{3}$, and $P_{4}$ in $\Omega$, as shown in Figure 2(c)

(c) If $0<R_{0}<\left(\beta_{2} / c\right)$, there exist four fixed points $P_{1}, P_{2}$, $P_{3}$, and $P_{4}$ in $\Omega$, as shown in Figure 2(a)

(d) If $R_{0}>\left(\beta_{2} / c\right)$, there exist three fixed points $P_{1}, P_{2}$, and $P_{3}$ in $\Omega$, as shown in Figure 2(b) 


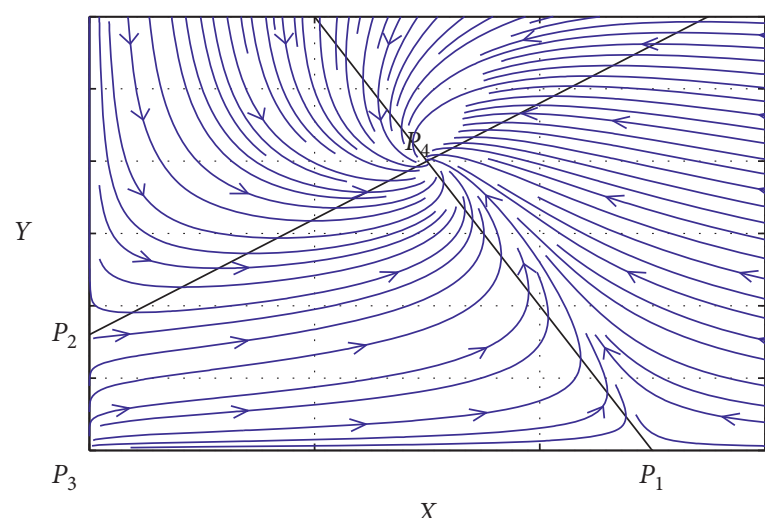

(a)

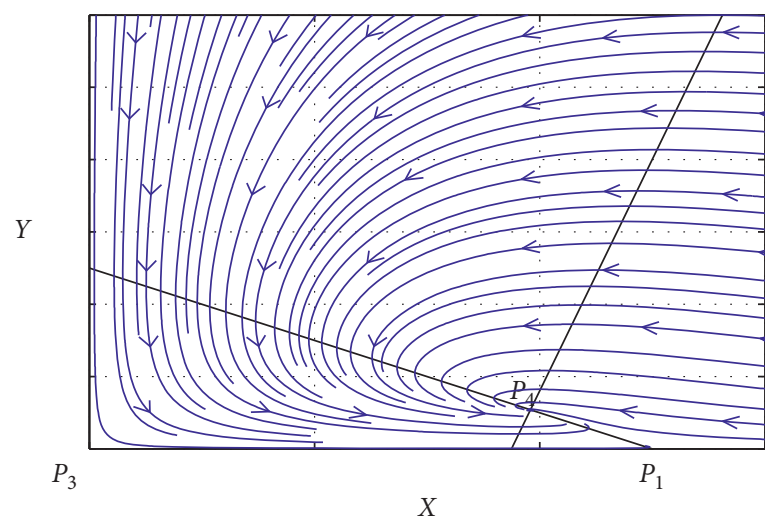

(c)



(b)

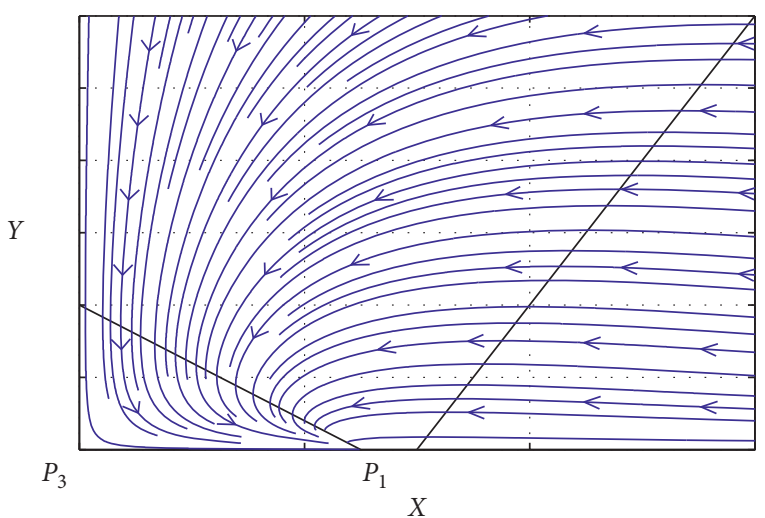

(d)

Figure 2: Phase diagrams: (a) $0<R_{0}<\left(\beta_{2} / c\right)$; (b) $R_{0}>\left(\beta_{2} / c\right)$; (c) $-\left(k c / \beta_{1}\right)<R_{0}<0$; (d) $R_{0}<-\left(k c / \beta_{1}\right)$.

In the next part, we analyze the stability condition of these fixed points based on Lyapunov's nonlinear stability theory.

\section{Stability Analysis}

Theorem 1. In the case of $R_{0}<-\left(k c / \beta_{1}\right)$, the fixed point $P_{1}$ of (4) is asymptotically stable in $\Omega$. If $R_{0}>-\left(k c / \beta_{1}\right), P_{1}$ is unstable.

Proof. The Jacobian matrix of equations (4) at $P_{1}$ is

$$
J\left(P_{1}\right)=\left[\begin{array}{cc}
-\left(a_{1}+a_{2}\right) & -c \frac{\left(a_{1}+a_{2}\right)}{\beta_{1}} \\
0 & \left(b_{1}-b_{2}\right)+k c \frac{\left(a_{1}+a_{2}\right)}{\beta_{1}}
\end{array}\right] .
$$

One of the eigenvalues of $J\left(P_{1}\right)$ is $\lambda_{1}=-\left(a_{1}+a_{2}\right)<0$. The other eigenvalue $\lambda_{2}=\left(b_{1}-b_{2}\right)+\left(k c\left(a_{1}+a_{2}\right) / \beta_{1}\right)$ $=\left(a_{1}+a_{2}\right)\left(R_{0}+\left(k c / \beta_{1}\right)\right) . \lambda_{2}$ is negative if and only if $R_{0}<-\left(k c / \beta_{1}\right)$.

By Lyapunov's first method for stability, the fixed point $P_{1}$ is asymptotically stable in $\Omega$ if $R_{0}<-\left(k c / \beta_{1}\right)$.
Theorem 2. In the case of $R_{0}>\left(\beta_{2} / c\right)$, the fixed point $P_{2}$ of (4) is asymptotically stable in $\Omega$. If $0<R_{0}<\left(\beta_{2} / c\right), P_{2}$ is unstable.

Proof. The Jacobian matrix of equations (4) at fixed point $P_{2}$ is

$$
J\left(P_{2}\right)=\left[\begin{array}{cc}
\left(a_{1}+a_{2}\right)-c \frac{\left(b_{1}-b_{2}\right)}{\beta_{2}} & 0 \\
k c \frac{\left(b_{1}-b_{2}\right)}{\beta_{2}} & -\left(b_{1}-b_{2}\right)
\end{array}\right] .
$$

The two eigenvalues of $J\left(P_{2}\right)$ are $\lambda_{1}=a_{1}+a_{2}-c\left(\left(b_{1}-\right.\right.$ $\left.\left.b_{2}\right) / \beta_{2}\right)=\left(a_{1}+a_{2}\right)\left(1-\left(c / \beta_{2}\right) R_{0}\right)$ and $\lambda_{2}=-\left(b_{1}-b_{2}\right)=-$ $\left(a_{1}+a_{2}\right) R_{0}$. All eigenvalues of $J\left(P_{2}\right)$ are negative if and only if $R_{0}>\left(\beta_{2} / c\right)$.

By Lyapunov's first method for stability, the fixed point $P_{2}$ is asymptotically stable in $\Omega$ if $R_{0}>\left(\beta_{2} / c\right)$.

Theorem 3. The fixed point $P_{3}$ of (4) is unstable.

Proof. The Jacobian matrix of equations (4) at fixed point $P_{3}$ is 


$$
J\left(P_{3}\right)=\left[\begin{array}{cc}
a_{1}+a_{2} & 0 \\
0 & b_{1}-b_{2}
\end{array}\right] .
$$

One of the eigenvalues of $J\left(P_{3}\right)$ is $\lambda_{1}=a_{1}+a_{2}>0$. Therefore, $P_{3}$ is an unstable equilibrium point.
Theorem 4. In the case of $-\left(k c / \beta_{1}\right)<R_{0}<\left(\beta_{2} / c\right)$, the fixed point $P_{4}$ of (4) is asymptotically stable in $\Omega$.

Proof. The Jacobian matrix of equation (4) at fixed point $P_{4}$ is

$$
J\left(P_{4}\right)=\left[\begin{array}{lc}
\frac{\left(b_{1}-b_{2}\right) c \beta_{1}-\left(a_{1}+a_{2}\right) \beta_{1} \beta_{2}}{\beta_{1} \beta_{2}+k c^{2}} & \frac{\left(b_{1}-b_{2}\right) c^{2}-\left(a_{1}+a_{2}\right) c \beta_{2}}{\beta_{1} \beta_{2}+k c^{2}} \\
\frac{k^{2}\left(a_{1}+a_{2}\right) c^{2}+k\left(b_{1}-b_{2}\right) c \beta_{1}}{\beta_{1} \beta_{2}+k c^{2}} & \frac{-k\left(a_{1}+a_{2}\right) c \beta_{2}-\left(b_{1}-b_{2}\right) \beta_{1} \beta_{2}}{\beta_{1} \beta_{2}+k c^{2}}
\end{array}\right] .
$$

The two eigenvalues of $J\left(P_{4}\right), \lambda_{1}$ and $\lambda_{2}$, satisfy the following equations:

$$
\begin{aligned}
\lambda_{1}+\lambda_{2} & =\frac{\left(b_{1}-b_{2}\right) c \beta_{1}-\left(a_{1}+a_{2}\right) \beta_{1} \beta_{2}-k\left(a_{1}+a_{2}\right) c \beta_{2}-\left(b_{1}-b_{2}\right) \beta_{1} \beta_{2}}{\beta_{1} \beta_{2}+k c^{2}}, \\
\lambda_{1} \lambda_{2} & =\frac{k c \beta_{2}\left(a_{1}+a_{2}\right)^{2}+\left(\beta_{1} \beta_{2}-k c^{2}\right)\left(a_{1}+a_{2}\right)\left(b_{1}-b_{2}\right)-c \beta_{1}\left(b_{1}-b_{2}\right)^{2}}{\beta_{1} \beta_{2}+k c^{2}} .
\end{aligned}
$$

Thus, we get

$$
\begin{aligned}
\lambda_{1}+\lambda_{2} & =\frac{a_{1}+a_{2}}{\beta_{1} \beta_{2}+k c^{2}}\left(\beta_{1} c\left(R_{0}-\frac{\beta_{2}}{c}\right)-\beta_{1} \beta_{2}\left(R_{0}+\frac{k c}{\beta_{1}}\right)\right), \\
\lambda_{1} \lambda_{2} & =-\frac{c \beta_{1}\left(a_{1}+a_{2}\right)^{2}}{\beta_{1} \beta_{2}+k c^{2}}\left(R_{0}-\frac{\beta_{2}}{c}\right)\left(R_{0}+\frac{k c}{\beta_{1}}\right) .
\end{aligned}
$$

Under the given condition $-\left(k c / \beta_{1}\right)<R_{0}<\left(\beta_{2} / c\right)$, we have $\lambda_{1}+\lambda_{2}<0$ and $\lambda_{1} \lambda_{2}>0$. Thus, $\lambda_{1}<0$ and $\lambda_{2}<0$. Therefore, the fixed point $P_{4}$ of (4) is asymptotically stable in $\Omega$ if $-\left(k c / \beta_{1}\right)<R_{0}<\left(\beta_{2} / c\right)$.

Figure 2 shows the fixed points and the phase diagrams of (4) when different coefficients are chosen. follows:

Through Theorems 1-4, we can achieve results as

(1) If $R_{0}<-\left(k c / \beta_{1}\right), P_{1}$ is the only asymptotically stable point among the two fixed points in Figure 2(d), corresponding to the low payoff condition

(2) If $R_{0}>\left(\beta_{2} / c\right), P_{2}$ is the only asymptotically stable point among the three fixed points in Figure 2(b), corresponding to the high payoff condition

(3) If $-\left(k c / \beta_{1}\right)<R_{0}<\left(\beta_{2} / c\right)$, the fixed point $P_{4}$ is the only asymptotically stable point both in Figures 2 (a) and 2(c), corresponding to payoff conditions acceptable to both employers and employees
When the payoff rate $c$ is set to be an optimal value, employers and employees in long run both come to a stable status with a larger amount of newly acquired resources than in the beginning. This constitutes a win-win situation. To achieve the win-win situation, the following conditions (15) $\left(b_{1}>b_{2}\right)$ or $(16)\left(b_{1}<b_{2}\right)$ should be satisfied. $\left(X_{0}, Y_{0}\right)$ is the initial resource value:

$$
\begin{aligned}
& \left\{\begin{array}{l}
\frac{\left(a_{1}+a_{2}\right) \beta_{2}-\left(b_{1}-b_{2}\right) c}{\beta_{1} \beta_{2}+k c^{2}}>X_{0}, \\
\frac{k\left(a_{1}+a_{2}\right) c+\left(b_{1}-b_{2}\right) \beta_{1}}{\beta_{2} \beta_{1}+k c^{2}}>Y_{0} \\
0<c<\frac{\beta_{2}}{R_{0}},
\end{array}\right. \\
& \left\{\begin{array}{l}
\frac{\left(a_{1}+a_{2}\right) \beta_{2}-\left(b_{1}-b_{2}\right) c}{\beta_{1} \beta_{2}+k c^{2}}>X_{0}, \\
\frac{k\left(a_{1}+a_{2}\right) c+\left(b_{1}-b_{2}\right) \beta_{1}}{\beta_{2} \beta_{1}+k c^{2}}>Y_{0}, \\
c>-\frac{\beta_{1} R_{0}}{k} .
\end{array}\right.
\end{aligned}
$$

By solving the equations, we can get the range of the payoff rate $c$ in the win-win situation. 
If $b_{1}>b_{2}, c$ satisfies

$$
\left\{\begin{array}{l}
\frac{\left(b_{2}-b_{1}\right)-\sqrt{\left(b_{1}-b_{2}\right)^{2}-4 k X_{0}\left(X_{0} \beta_{1}-\left(a_{1}+a_{2}\right)\right) \beta_{2}}}{2 k X_{0}}<c<\frac{\left(b_{2}-b_{1}\right)+\sqrt{\left(b_{1}-b_{2}\right)^{2}-4 k X_{0}\left(X_{0} \beta_{1}-\left(a_{1}+a_{2}\right)\right) \beta_{2}}}{2 k X_{0}}, \\
\frac{k\left(a_{1}+a_{2}\right)-\sqrt{k^{2}\left(a_{1}+a_{2}\right)^{2}-4 k Y_{0}\left(Y_{0} \beta_{2}-\left(b_{1}-b_{2}\right)\right) \beta_{1}}}{2 k Y_{0}}<c<\frac{k\left(a_{1}+a_{2}\right)+\sqrt{k^{2}\left(a_{1}+a_{2}\right)^{2}-4 k Y_{0}\left(Y_{0} \beta_{2}-\left(b_{1}-b_{2}\right)\right) \beta_{1}}}{2 k Y_{0}}, \\
0<c<\frac{\left(a_{1}+a_{2}\right) \beta_{2}}{b_{1}-b_{2}} .
\end{array}\right.
$$

If $b_{1}<b_{2}, c$ satisfies

$$
\left\{\begin{array}{l}
\frac{\left(b_{2}-b_{1}\right)-\sqrt{\left(b_{1}-b_{2}\right)^{2}-4 k X_{0}\left(X_{0} \beta_{1}-\left(a_{1}+a_{2}\right)\right) \beta_{2}}}{2 k X_{0}}<c<\frac{\left(b_{2}-b_{1}\right)+\sqrt{\left(b_{1}-b_{2}\right)^{2}-4 k X_{0}\left(X_{0} \beta_{1}-\left(a_{1}+a_{2}\right)\right) \beta_{2}}}{2 k X_{0}}, \\
\frac{k\left(a_{1}+a_{2}\right)-\sqrt{k^{2}\left(a_{1}+a_{2}\right)^{2}-4 k Y_{0}\left(Y_{0} \beta_{2}-\left(b_{1}-b_{2}\right)\right) \beta_{1}}}{2 k Y_{0}}<c<\frac{k\left(a_{1}+a_{2}\right)+\sqrt{k^{2}\left(a_{1}+a_{2}\right)^{2}-4 k Y_{0}\left(Y_{0} \beta_{2}-\left(b_{1}-b_{2}\right)\right) \beta_{1}}}{2 k Y_{0}}, \\
c>-\frac{\beta_{1}\left(b_{1}-b_{2}\right)}{k\left(a_{1}+a_{2}\right)}
\end{array}\right.
$$

\section{Numerical Examples}

Dynamic evolution of the resources owned by employers and employees is governed by equation (4). We simulate numerical solutions of the equations using Matlab. Four cases, including employer win, employee win, lose-lose, and win-win, are discussed and analyzed. In particular, the strategy space of the payoff rate $c$ leading to the win-win situation is provided.

The values of parameters in the four cases are partially based on the real labor disputes, which had similar circumstances, but different endings in the dispute because of different strategies.

5.1. Employer Win Situation. Given the initial value $\left(X_{0}, Y_{0}\right)=(1,0.2)$ and the parameters $a_{1}=0.4, a_{2}=0.1$, $b_{1}=0.1, b_{2}=0.7, \beta_{1}=0.2, \beta_{2}=0.1, k=0.8$, and $c=0.25$, we have $R_{0}=-1.2$, which is smaller than $-\left(k c / \beta_{1}\right)=-1$. Therefore, it will eventually reach the fixed point $P_{1}=(2.5,0)$. The simulation result is illustrated in Figure 3(a), and the phase trail is shown in Figure 3(b).

The numerical simulation shows that it favors employers in this situation, in which employers provide low payoffs to employees and obtain continuing growth in resources. On the contrary, employees do not harvest from their work due to low payoffs. The employer win situation is unsustainable. As time evolves, resources are overwhelmingly possessed by employers while employees own less and less. This is a situation called employer win.

5.2. Employee Win Situation. Given the initial value $\left(X_{0}, Y_{0}\right)=(1,0.2)$ and the parameters $a_{1}=0.4, a_{2}=0.1$, $b_{1}=0.1, b_{2}=0.02, \beta_{1}=0.2, \beta_{2}=0.1, k=0.8$, and $c=0.8$, we have $R_{0}=0.16$, which is larger than $\left(\beta_{2} / c\right)=0.125$. Therefore, it will eventually reach the fixed point $P_{2}=(0,0.8)$. The simulation result is illustrated in Figure 4(a), and the phase trail is shown in Figure 4(b).

The numerical simulation shows employees will tend to have the continuing increase of resources with high payoffs. On the contrast, employers will suffer a high operation cost of production activity and their resources no longer increase with time. In all, it is a case of employee win.

5.3. Lose-Lose Situation. Given the initial value $\left(X_{0}, Y_{0}\right)=$ $(1,0.2)$ and the parameters $a_{1}=0.4, a_{2}=0.1, b_{1}=0.1$, 


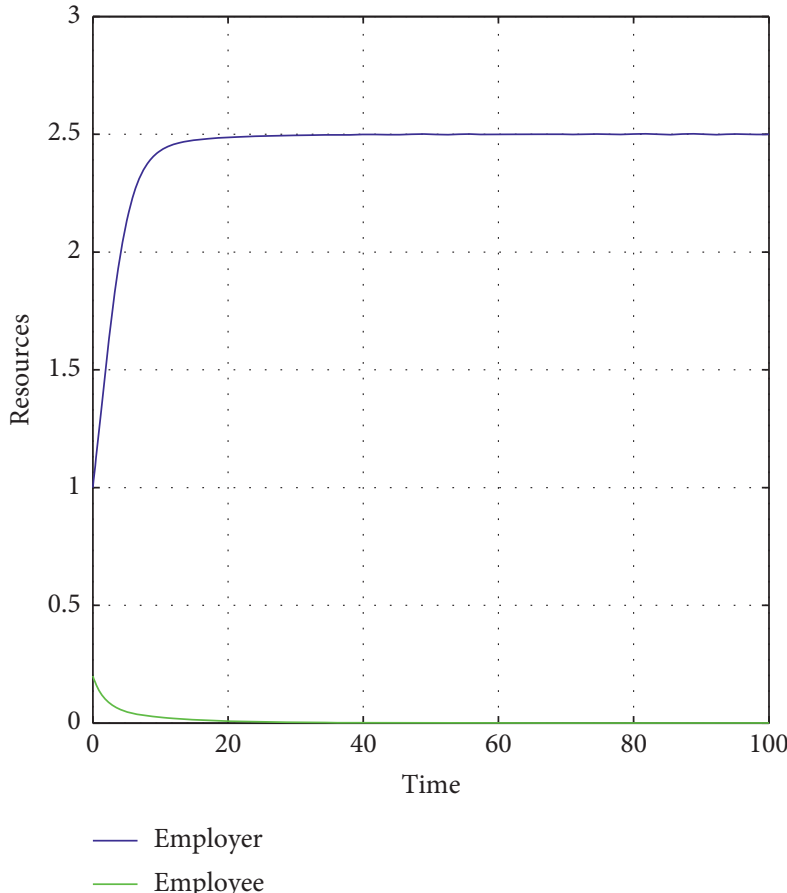

(a)

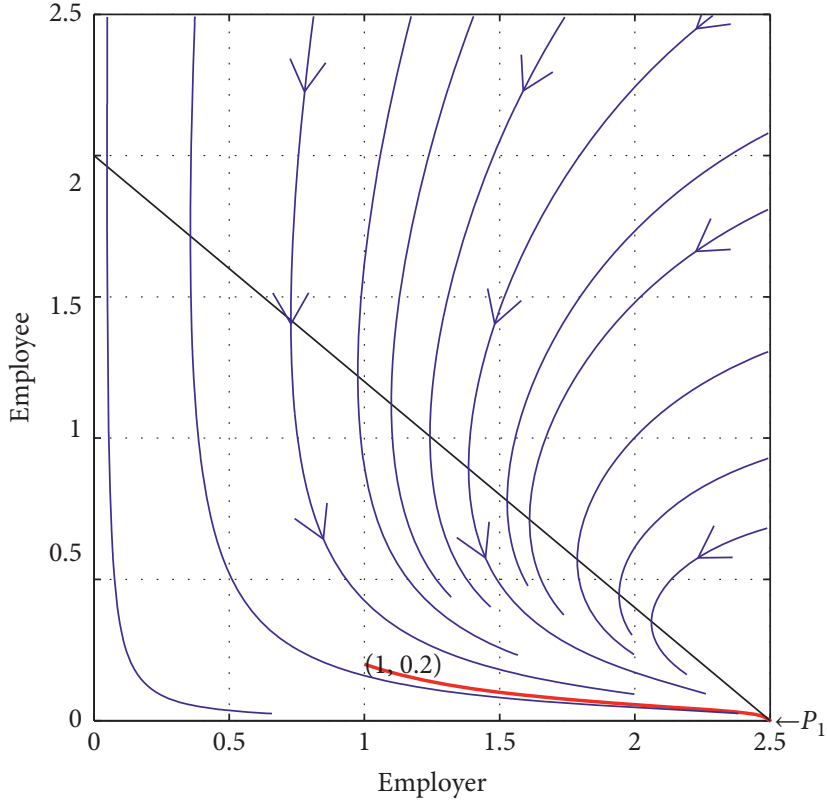

(b)

FIgURE 3: The simulation result and the phase diagram in the employer win situation.



(a)

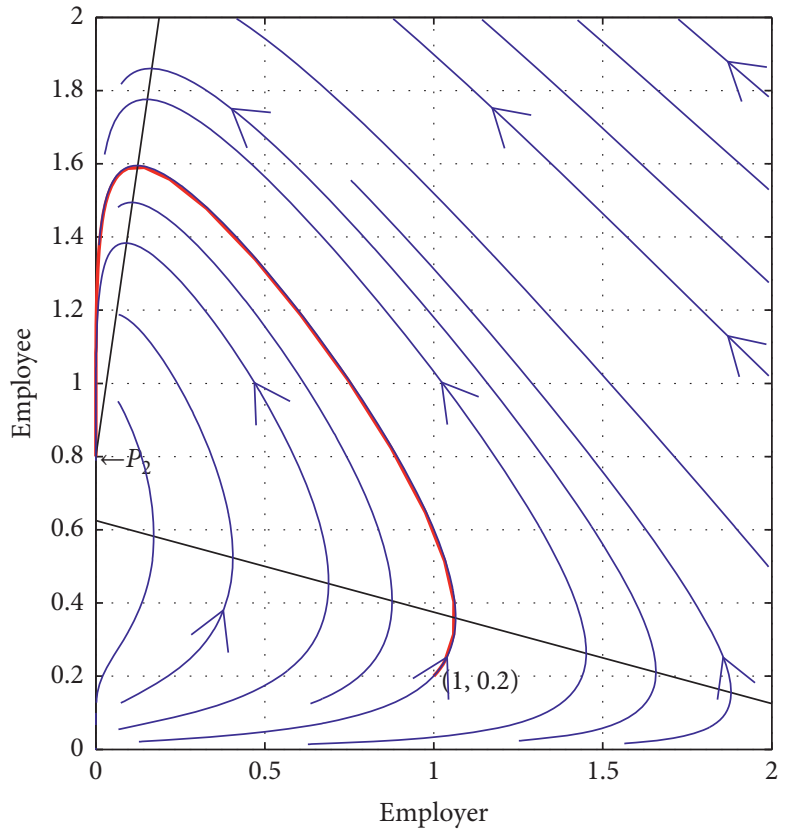

(b)

FIgURE 4: The simulation result and the phase diagram in the employee win situation.

$b_{2}=0.7, \beta_{1}=0.5, \beta_{2}=0.5, k=0.8$, and $c=0.9$, we have $R_{0}=-1.2$, which is negative and larger than $-\left(k c / \beta_{1}\right)=$ -1.44 . Therefore, it will eventually reach the fixed point
$P_{4}=((395 / 449),(30 / 449))$. The simulation result is illustrated in Figure 5(a), and the phase trail is shown in Figure 5(b). 


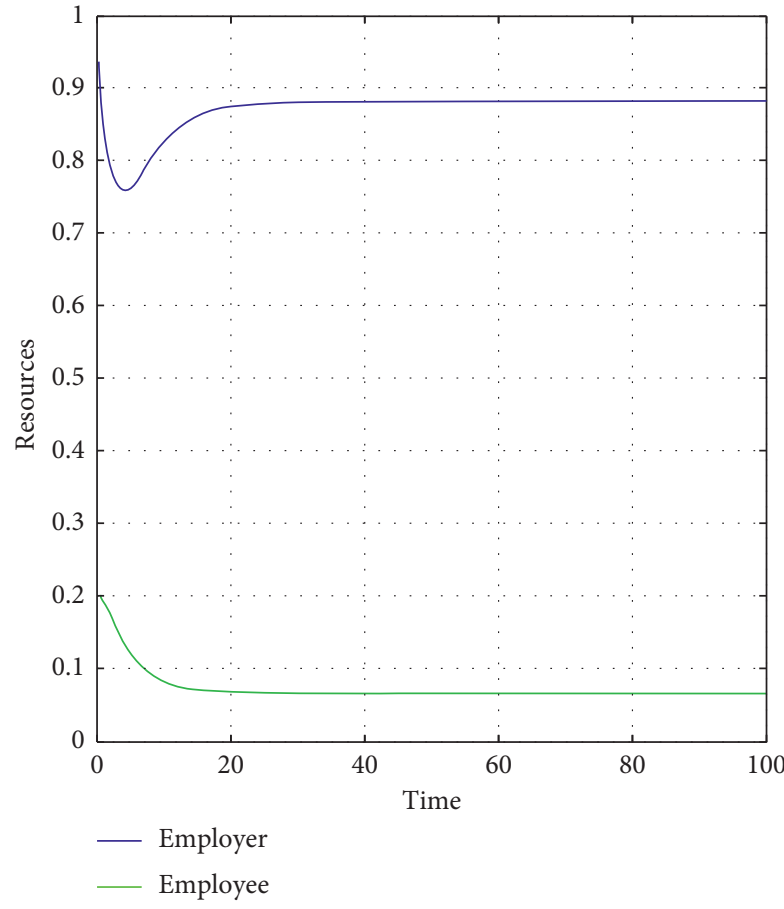

(a)

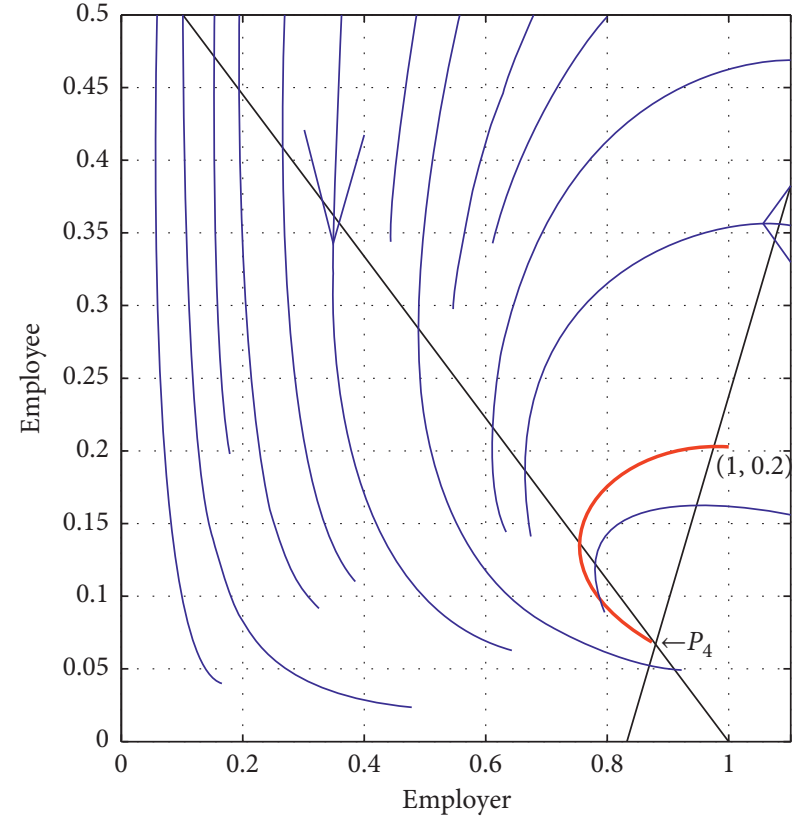

(b)

Figure 5: The simulation result and the phase diagram in the lose-lose situation.

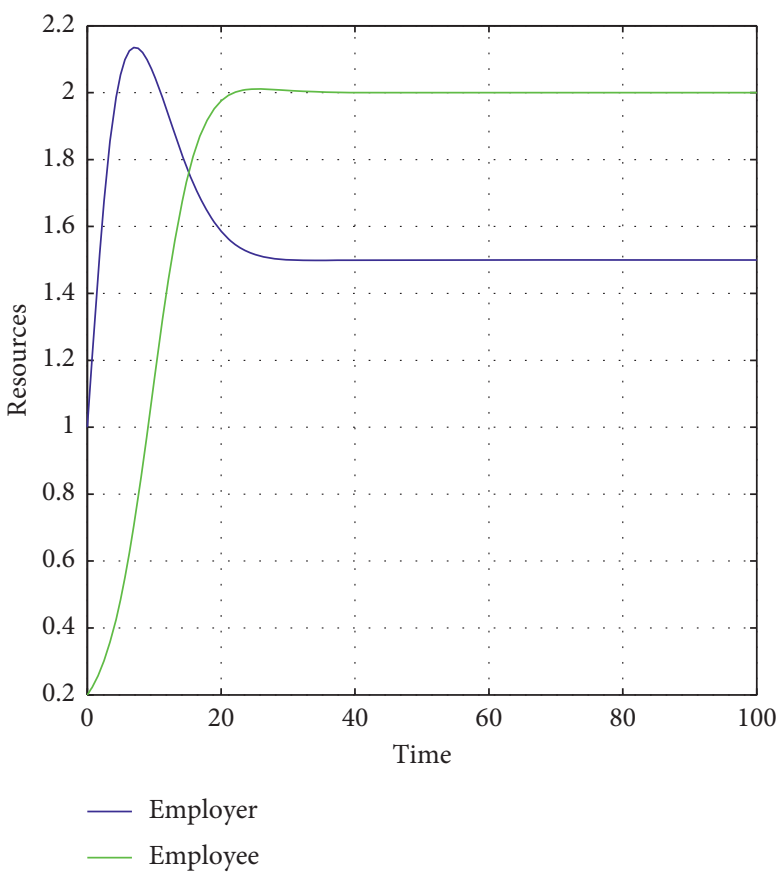

(a)

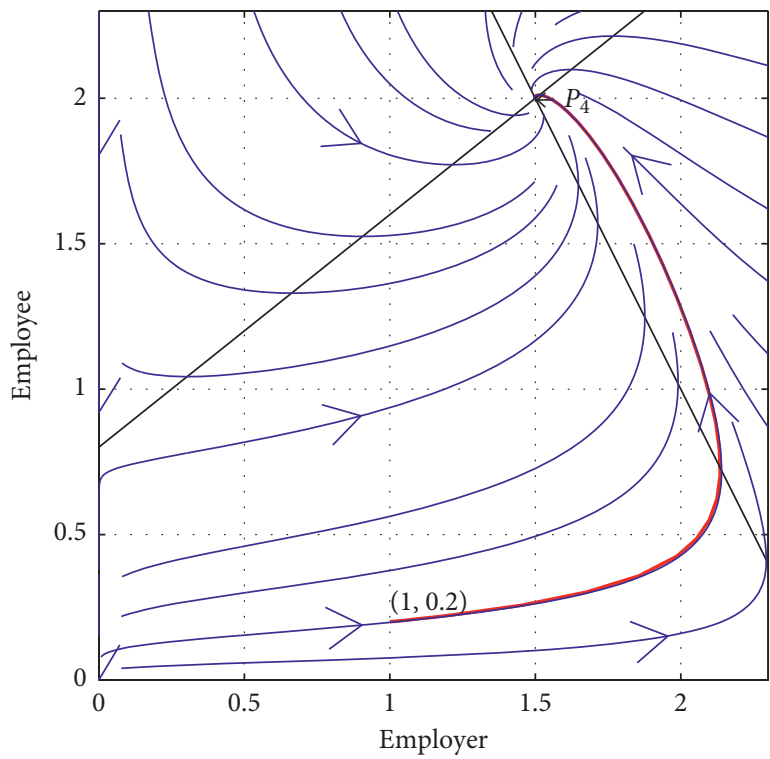

(b)

Figure 6: The simulation result and the phase diagram in the win-win situation $\left(b_{1}>b_{2}\right)$.

The numerical simulation shows that when payoff rate $c$ is specifically set, both parties decline to reach a lose-lose situation with the decrease of newly acquired resources. In this case, the payoff turns out to be a burden to employers and drags down the production output in long run, while it cannot feed up the employees. The phase diagram shows that newly acquired resources of the two parties in long run would be less compared to those in the initial stage. 


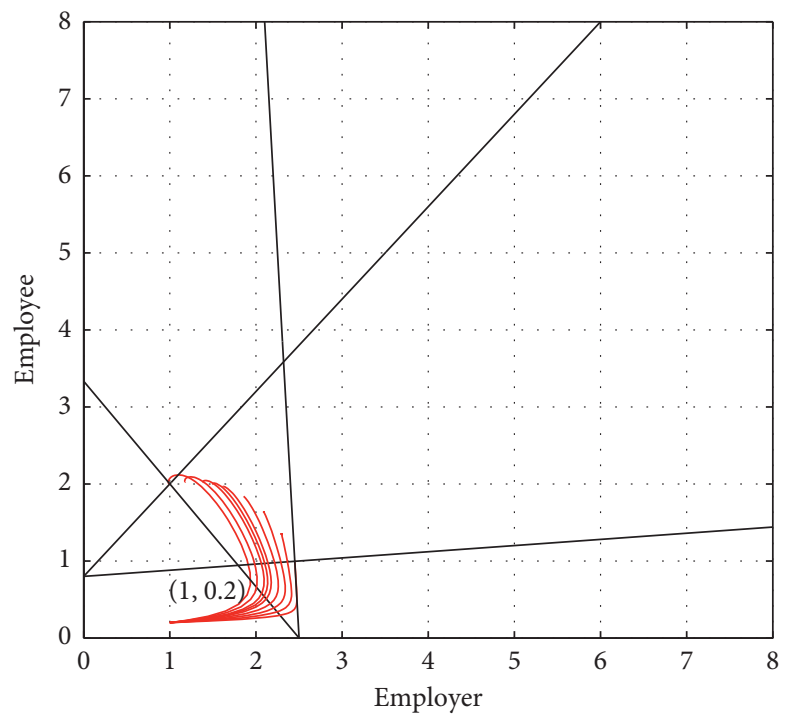

Figure 7: Simulation result with various $c\left(b_{1}>b_{2}\right)$.



(a)

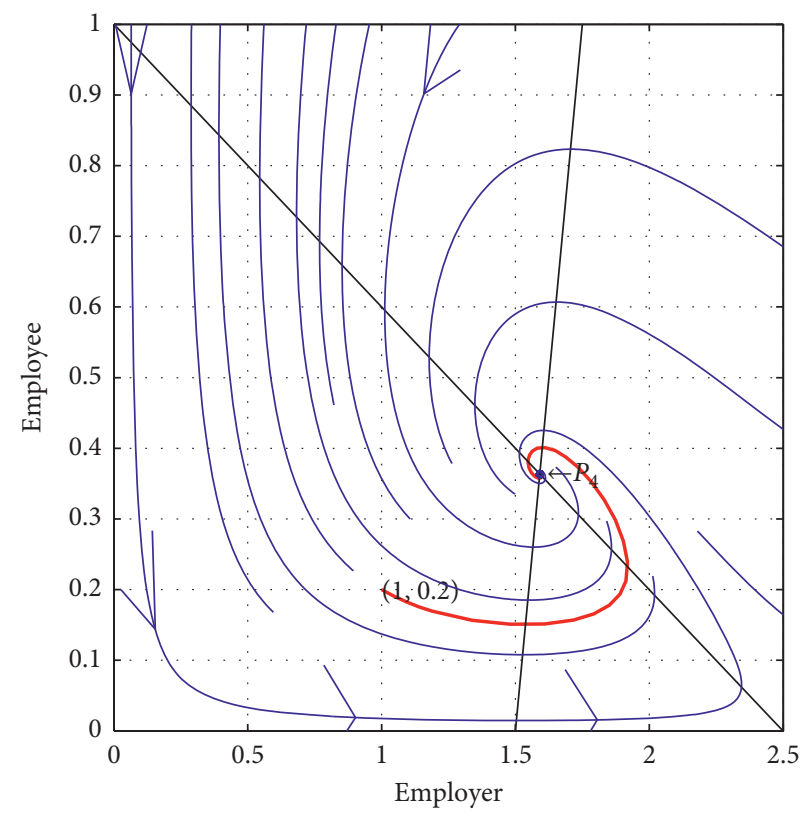

(b)

Figure 8: The simulation result and the phase diagram in the win-win situation $\left(b_{1}<b_{2}\right)$.

5.4. Win-Win Situation. If $b_{1}>b_{2}$, given the initial value $\left(X_{0}, Y_{0}\right)=(1,0.2)$ and the parameters $a_{1}=0.4, a_{2}=0.1$, $b_{1}=0.1, b_{2}=0.02, \beta_{1}=0.2, \beta_{2}=0.1, k=0.8$, and $c=0.1$, we have $R_{0}=0.16$, which is positive and smaller than $\left(\beta_{2} / c\right)=1$. Therefore, it will eventually reach the fixed point $P_{4}=(1.5,2)$. The simulation result is illustrated in Figure 6(a), and the phase trail is shown in Figure 6(b).

In this case, $b_{1}>b_{2}$, so the payoff strategy space can be calculated by using equation (17). Keeping all other parameters unchanged, employers and employees can achieve a win-win situation if the payoff rate $c$ is chosen from interval $(0,0.15)$. The phase trail with different $c$ values is illustrated in Figure 7.

If $b_{1}<b_{2}$, given the initial value $\left(X_{0}, Y_{0}\right)=(1,0.2)$ and the parameters $a_{1}=0.4, a_{2}=0.1, b_{1}=0.1, b_{2}=0.7, \beta_{1}=0.2$, $\beta_{2}=0.1, k=0.8$, and $c=0.5$, we have $R_{0}=-1.2$, which is negative and larger than $-\left(k c / \beta_{1}\right)=-4$. Therefore, it will eventually reach the fixed point $P_{4}=((35 / 22),(4 / 11))$. The 


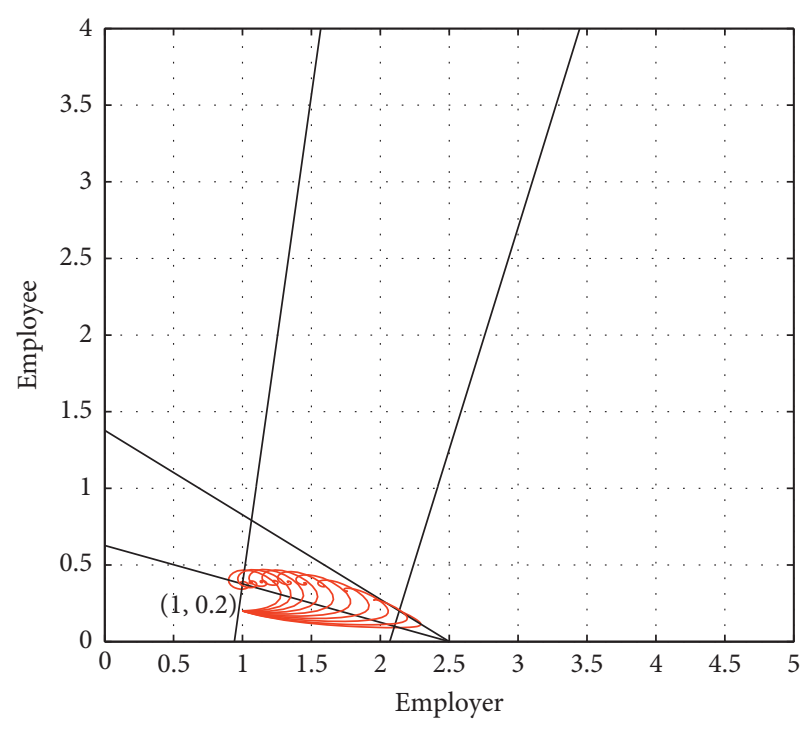

Figure 9: Simulation results with various $c\left(b_{1}<b_{2}\right)$.

simulation result is illustrated in Figure 8(a), and the phase trail is shown in Figure 8(b).

In this case, $b_{1}<b_{2}$, so the payoff strategy space can be calculated by using equation (18). Keeping all other parameters unchanged, employers and employees can achieve a win-win situation if the payoff rate $c$ is chosen from interval $(((25-3 \sqrt{35}) / 20),((15+\sqrt{285}) / 40))$. The phase trail with different $c$ values is illustrated in Figure 9.

The numerical simulation shows that when the payoff rate $c$ is set as an optimal value, both parties have a chance to reach a win-win situation with the continuously increase of resources. From the phase diagram, resources of two parties are both rising and the newly acquired resources will be larger than their initial values in the long run.

\section{Discussion and Conclusions}

The relationship between employees and employers that needs long-term cooperation was mutually interdependent, dynamic, and continually evolving. The two sides should be more concerned about the long-term benefits rather than immediate ones. As long as employees and employers rationally and compromisingly negotiated within a win-win strategy space, it was possible to find a strategy for both employees and employers to continually obtain resources above the initial value, achieving stable and sustainable development.

That is to say, there actually existed a unified model structure which could depict relationships of cooperation, competition, and symbiosis only by different coefficients. Comparatively, different dynamic models are adopted in traditional populations and ecological dynamic problems to describe the relationship of cooperation, competition, and symbiosis between species. In our model, changing strategies of the conflicting two sides could lead to relationships of competition, cooperation, and symbiosis, that is, changing coefficients of our unified model structure. By extension, it was possible for the conflicting two sides to obtain resources sustainably through cooperation instead of fierce conflicts.

In conclusion, the conflicts between social groups were not irreconcilable, but on the contrary, there indeed existed a win-win strategy space rather than an ideal point in theory. Therefore, there was not only an ideal theory, but a practical and optional space corresponding to various strategies which can be realized.

\section{Data Availability}

The data used to support the findings of this study were reported by the official public media.

\section{Conflicts of Interest}

The authors declare that they have no conflicts of interest.

\section{Acknowledgments}

This work was supported by the Major Program of National Social Science Foundation of China under Grant 11\&ZD174.

\section{References}

[1] C. K.-C. Chan and E. S.-I. Hui, "The development of collective bargaining in China: from "collective bargaining by riot" to "party state-led wage bargaining"," The China Quarterly, vol. 217, pp. 221-242, 2014.

[2] F. Chen, "Between the state and labour: the conflict of Chinese trade unions' double identity in market reform," The China Quarterly, vol. 176, pp. 1006-1028, 2003.

[3] J. Shen and J. Benson, "Tripartite consultation in China: a first step towards collective bargaining?," International Labour Review, vol. 147, no. 2-3, pp. 231-248, 2008.

[4] F. O. Oderanti, F. Li, and P. De Wilde, "Application of strategic fuzzy games to wage increase negotiation and decision problems," Expert Systems with Applications, vol. 39, no. 12, pp. 11103-11114, 2012.

[5] H. Houba and Q. Wen, "On striking for a bargain between two completely informed agents," Economic Theory, vol. 37, no. 3, pp. 509-519, 2008.

[6] S. A. Morris and D. Pratt, "Analysis of the Lotka-Volterra competition equations as a technological substitution model," Technological Forecasting and Social Change, vol. 70, no. 2, pp. 103-133, 2003.

[7] S. -J. Lee, D. -J. Lee, and H. -S. Oh, “Technological forecasting at the Korean stock market: a dynamic competition analysis using Lotka-Volterra model," Technological Forecasting and Social Change, vol. 72, no. 8, pp. 1044-1057, 2005.

[8] F. Dercole and S. A. H. Geritz, "Unfolding the resident-invader dynamics of similar strategies," Journal of Theoretical Biology, vol. 394, pp. 231-254, 2016.

[9] D. Pietraszewski, "How the mind sees coalitional and group conflict: the evolutionary invariances of $n$-person conflict dynamics," Evolution and Human Behavior, vol. 37, no. 6, pp. 470-480, 2016.

[10] J. M. Smith and G. R. Price, "The logic of animal conflict," Nature, vol. 246, no. 5427, pp. 15-18, 1973.

[11] M. Mesterton-Gibbons and T. N. Sherratt, "How residency duration affects the outcome of a territorial contest: complementary game-theoretic models," Journal of Theoretical Biology, vol. 394, pp. 137-148, 2016. 
[12] S. E. Gent and M. Shannon, "Bargaining power and the arbitration and adjudication of territorial claims," Conflict Management and Peace Science, vol. 31, no. 3, pp. 303-322, 2014.

[13] B. Nunes, R. C. Alamino, D. Shaw, and D. Bennett, "Modelling sustainability performance to achieve absolute reductions in socio-ecological systems," Journal of Cleaner Production, vol. 132, pp. 32-44, 2016.

[14] J. Hofbauer and K. Sigmund, Evolutionary Games and Population Dynamics, Cambridge University Press, Cambridge, UK, 1998. 


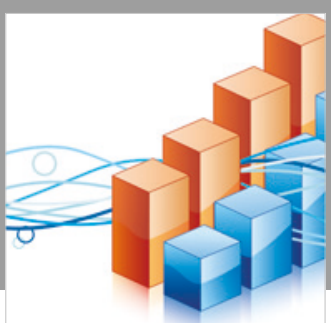

Advances in

Operations Research

\section{-n-m}
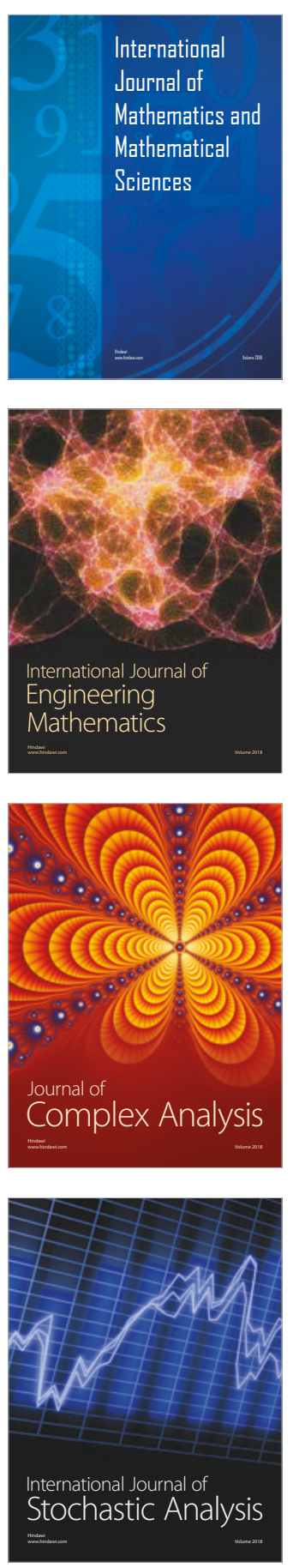
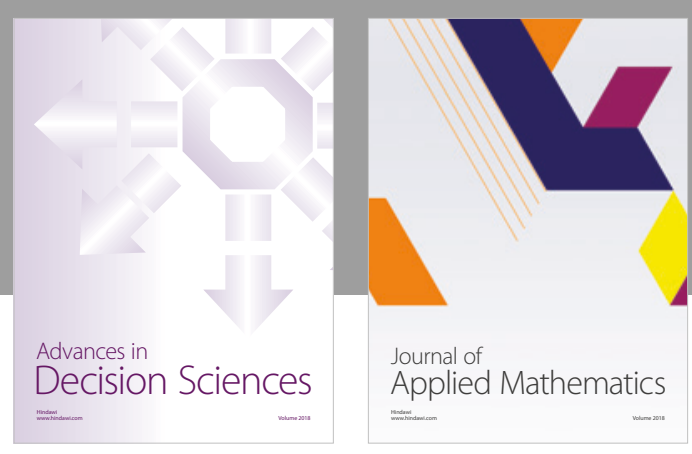

Journal of

Applied Mathematics


Submit your manuscripts at

www.hindawi.com

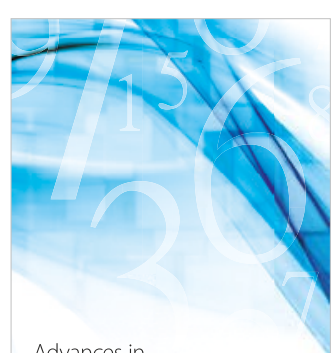

Advances in
Numerical Analysis
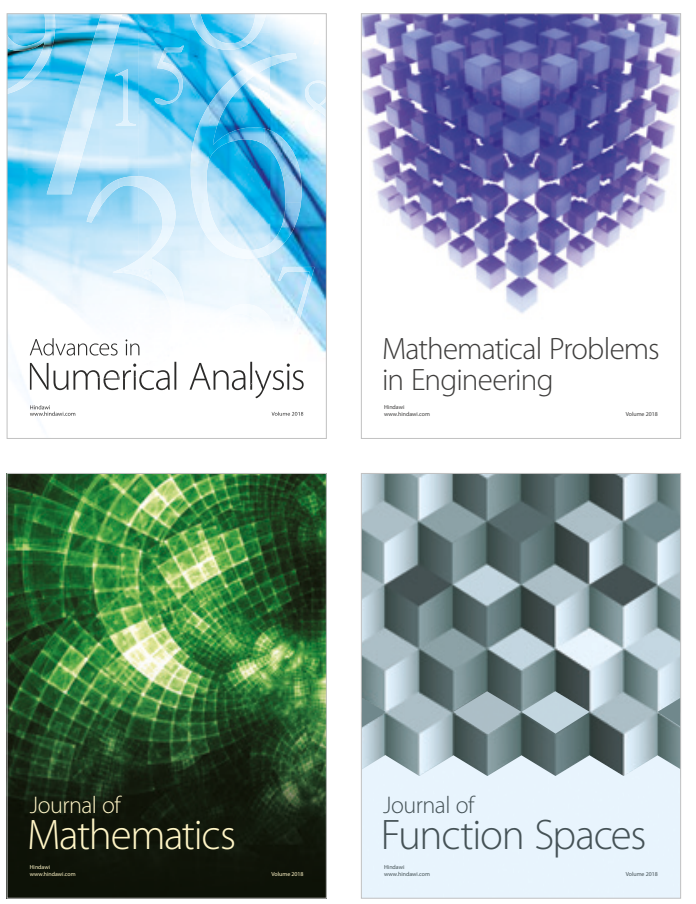

Mathematical Problems in Engineering

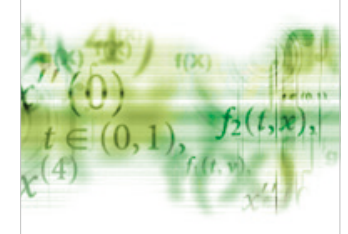

International Journal of

Differential Equations

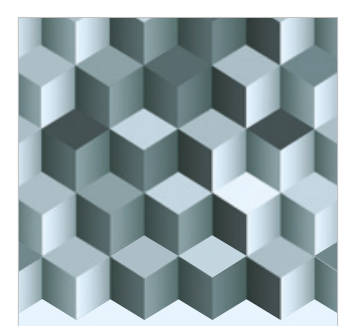

Journal of

Function Spaces
The Scientific

World Journal

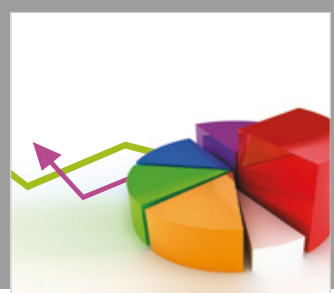

Journal of

Probability and Statistics
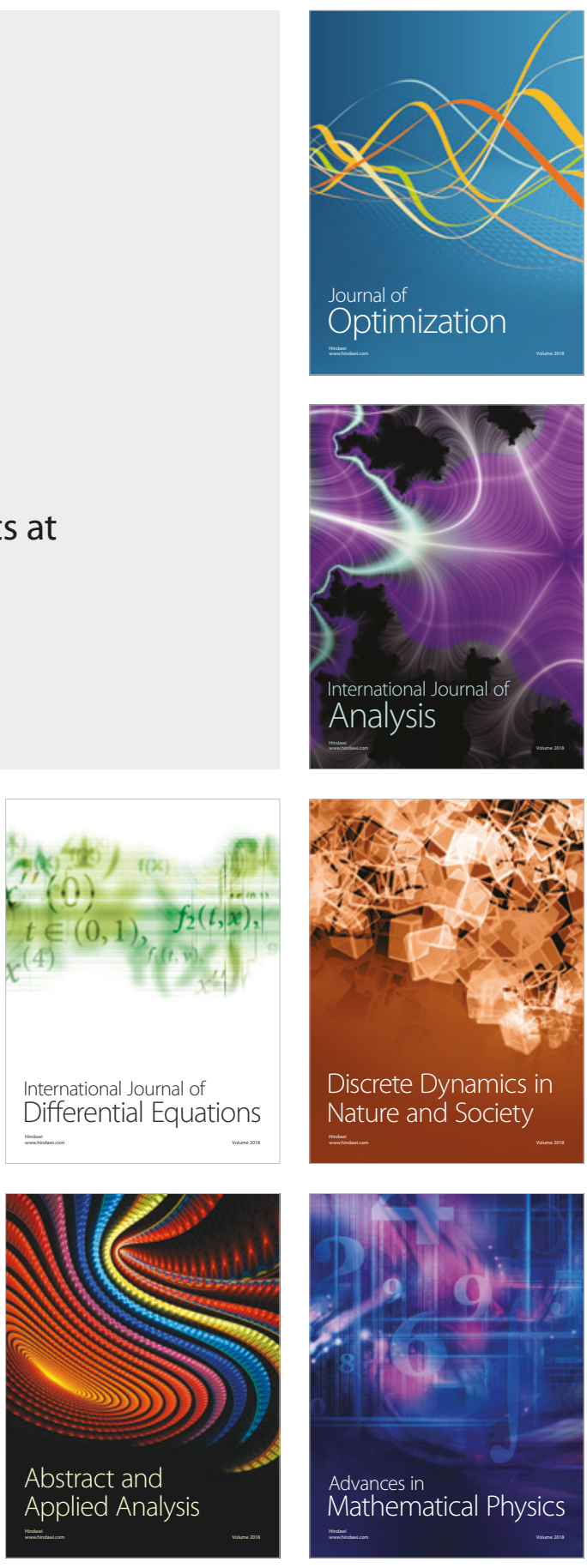